\title{
Theoretical Description for Ellagic Acid Electrochemical Oxidation and Electropolymerization
}

\author{
Volodymyr V. Tkach ${ }^{1,2}{ }^{\mathbb{D}}$, Marta V. Kushnir ${ }^{1 \mathbb{D}}$, Sílvio C. de Oliveira ${ }^{2}{ }^{\mathbb{D}}$, Yana G. Ivanushko ${ }^{3(\mathbb{D})}$, \\ Viktoria O. Tkach ${ }^{4}(\mathbb{D})$, Hanna Ya. Mytrofanova ${ }^{4}\left(\mathbb{D}\right.$, Anatolii O. Zadoia ${ }^{4}$, Petro I. Yagodynets ${ }^{1(\mathbb{D})}$, \\ Zholt O. Kormosh 5 (D) , Olga V. Luganska 6 (iD \\ 1 Chernivtsi National University, 58000, Kotsyubyns 'ky Str. 2, Chernivtsi, Ukraine \\ 2 Universidade Federal de Mato Grosso do Sul, Av. Sen. Felinto. Müller, 1555, C/P. 549, 79074-460, Campo Grande, MS, \\ Brazi \\ Bukovinian State Medical University, 58001, Teatralna Sq., 9, Chernivtsi Ukraine \\ 4 Alfred Nobel University, 49000, Naberezhna Sicheslavska Str., 18, Dnipro, Ukraine \\ 5 EasternEuropean National University, 43000, Voli Ave., 13, Lutsk, Ukraine \\ * Correspondence: nightwatcher2401@gmail.com (V.V.T.);
}

Scopus Author ID 55758299100

Received: 10.05.2021; Revised: 15.07.2021; Accepted: 19.07.2021; Published: 7.09.2021

\begin{abstract}
The theoretical description for ellagic acid electrochemical oxidation and electropolymerization has been suggested in this paper. The model includes the electropolymerization of ellagic acid in the presence of two of its low-molecular oxidation products. The correspondent mathematical model has been developed and analyzed using linear stability theory and bifurcation analysis. The analysis of the system has confirmed that the oscillatory behavior is more probable than in the simplest case of the electrosynthesis of the polymer of the electrochemically synthesized monomer. Nevertheless, the system is electrosynthetically efficient, yielding a polymer coating.
\end{abstract}

Keywords: ellagic acid; electrochemical oxidation; hydroquinonic compounds; electrochemical polymerization; conducting polymers; stable steady-state.

(C) 2021 by the authors. This article is an open-access article distributed under the terms and conditions of the Creative Commons Attribution (CC BY) license (https://creativecommons.org/licenses/by/4.0/).

\section{Introduction}

Hydroquinone compounds constitute one of the most popular electrochemically active compound series [1-6]. They are useful for either electroanalytical or electrosynthetical points of view. For example, they may be a renewable material for conducting polymers and their dopants.

One of these compounds may be ellagic acid [7-9] (Fig. 1). It is a natural compound from pomegranate, known from the $5^{\text {th }}$ Century BC. Its biological properties include antioxidant, anti-inflammatory, and hepatoprotective. Pomegranate is named by the seed-like pulp (from Spanish "grano" meaning "seed") and gave the name to the Spanish city of Granada.

It is known that the alimentary properties of the pomegranate juice are dependent on different factors, including the location of the fruit growth, the age of the juice, and the condition of its storage $[10,11]$, and the ellagic acid is one of the markers of those properties, the reason why the electrochemical determination of the ellagic acid is actual [12-14]. 
<smiles>O=c1oc2c(O)c(O)cc3c(=O)oc4c(O)c(O)cc1c4c23</smiles>

Figure 1. Ellagic acid.

Also, considering the ellagic acid composition, it is possible to conclude that it may serve as either monomer or dopant for conducting polymers, as it is characteristic of hydroquinone compounds [15-18].

Nevertheless, the ellagic acid electrochemical oxidation mechanism may be realized by two parallel mechanisms, each of which impacts the system's behavior. Moreover, this process tends to be accompanied by electrochemical instabilities, typical for this similar electrooxidation and electropolymerization systems [19, 20].

Therefore, the goal of this work is to describe the electrochemical behavior of ellagic acid theoretically during its electrochemical oxidation. It will be realized by the model development and analysis using linear stability theory and bifurcation analysis. Also, the system's behavior will be compared to those of similar systems [21-24]

\section{Materials and Methods}

\subsection{System and its modeling.}

The electrochemical oxidation routs for the ellagic acid may be depicted in Fig. 2:

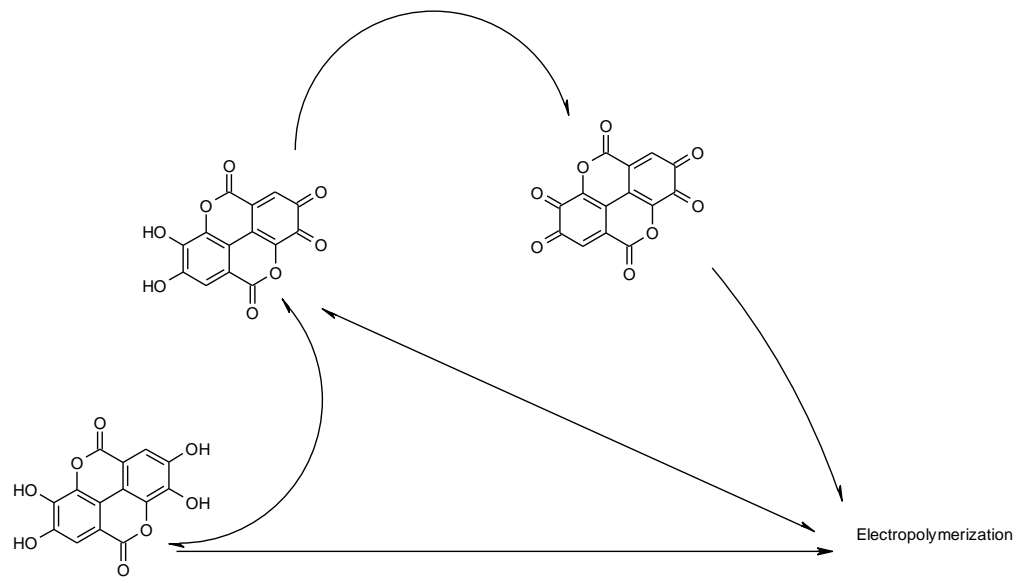

Figure 2. Ellagic acid electrooxidation scheme.

Being a hydroquinonic compound with two condensed hydroquinonic moieties, ellagic acid is electrooxidized gradually to the correspondent quinones. Another possible oxidation route is electropolymerization, known for dopamine and other hydroquinone compounds [15 18]. Either the reagent or both of the products are capable of entering the growing polymer chain.

Therefore, to describe the system with the electrochemical determination of ellagic acid, we introduce two variables: 
$\mathrm{q}_{1}$ - the first hydroquinone compound surface coverage degree;

$\mathrm{q}_{2}$ - the second hydroquinone compound surface coverage degree.

Assuming that ellagic acid covers the entire electrode surface, we may describe the behavior of the system as:

$$
\left\{\begin{array}{c}
\frac{d q_{1}}{d t}=\frac{1}{Q_{1}}\left(r_{1}-r_{2}-r_{p}\right) \\
\frac{d q_{2}}{d t}=\frac{1}{Q_{2}}\left(r_{2}-r_{p}\right)
\end{array}\right.
$$

Herein, $\mathrm{Q}_{1}$ and $\mathrm{Q}_{2}$ are the quinone compounds maximal concentrations, and the parameters $r$ are the correspondent electrochemical reaction rates, calculated as:

$$
\begin{gathered}
r_{1}=k_{1}\left(1-q_{1}-q_{2}\right) \exp \left(\frac{2 F \varphi_{0}}{R T}\right) \\
r_{2}=k_{2} q_{1} \exp \left(\frac{2 F \varphi_{0}}{R T}\right) \\
r_{p}=k_{p}\left(1-q_{1}-q_{2}\right)^{x} q_{1}^{y} q_{2}^{z} \exp \left(\frac{(2(x+y+z)-2) F \varphi_{0}}{R T}\right)
\end{gathered}
$$

Where the parameters $\mathrm{k}$ are the correspondent reaction rate constants, $\mathrm{x} \mathrm{y}$ and $\mathrm{z}$ are the correspondent reaction orders for the electropolymerization reaction (the electron number $2(x+y+z)-2)$ may be derived from the classical Díaz electropolymerization mechanism), $\mathrm{F}$ is the Faraday number, $\varphi_{0}$ is the potential slope, related to the zero-charge potential, $\mathrm{R}$ is the universal gas constant and $\mathrm{T}$ is the absolute temperature.

As this system is characterized by a chain of electrochemical systems, influencing the DEL and surface conductivity and impedance, the oscillatory behavior will be highly probable even in the simplest case. Nevertheless, the polymer has to be formed in an efficient manner, as shown below.

\section{Results and Discussion}

To describe the behavior of the system with the electrooxidation of ellagic acid yielding both quinone compounds and the polymer, we analyze the equation-set (1) using the linear stability theory. The steady-state Jacobian matrix members may be described as:

$$
\left(\begin{array}{ll}
a_{11} & a_{12} \\
a_{21} & a_{22}
\end{array}\right)
$$

Herein:

$$
\begin{aligned}
& a_{11}=\frac{1}{Q_{1}}\left(-k_{1} \exp \left(\frac{2 F \varphi_{0}}{R T}\right)+j k_{1}\left(1-q_{1}-q_{2}\right) \exp \left(\frac{2 F \varphi_{0}}{R T}\right)-k_{2} \exp \left(\frac{2 F \varphi_{0}}{R T}\right)+\right. \\
& j k_{2} q_{1} \exp \left(\frac{2 F \varphi_{0}}{R T}\right)+k_{p} x\left(1-q_{1}-q_{2}\right)^{x-1} q_{1}^{y} q_{2}^{z} \exp \left(\frac{(2(x+y+z)-2) F \varphi_{0}}{R T}\right)-y k_{p}\left(1-q_{1}-\right. \\
& \left.\left.q_{2}\right)^{x} q_{1}^{y-1} q_{2}^{z} \exp \left(\frac{(2(x+y+z)-2) F \varphi_{0}}{R T}\right)+j k_{p}\left(1-q_{1}-q_{2}\right)^{x} q_{1}^{y} q_{2}^{z} \exp \left(\frac{(2(x+y+z)-2) F \varphi_{0}}{R T}\right)\right) \\
& a_{12}=\frac{1}{Q_{1}}\left(-k_{1} \exp \left(\frac{2 F \varphi_{0}}{R T}\right)+l k_{1}\left(1-q_{1}-q_{2}\right) \exp \left(\frac{2 F \varphi_{0}}{R T}\right)-k_{p} x\left(1-q_{1}-\right.\right. \\
& \left.q_{2}\right)^{x-1} q_{1}^{y} q_{2}^{z} \exp \left(\frac{(2(x+y+z)-2) F \varphi_{0}}{R T}\right)-z k_{p}\left(1-q_{1}-q_{2}\right)^{x} q_{1}^{y} q_{2}^{z-1} \exp \left(\frac{(2(x+y+z)-2) F \varphi_{0}}{R T}\right)+ \\
& \left.l k_{p}\left(1-q_{1}-q_{2}\right)^{x} q_{1}^{y} q_{2}^{z} \exp \left(\frac{(2(x+y+z)-2) F \varphi_{0}}{R T}\right)\right)(7) \\
& a_{21}=\frac{1}{Q_{2}}\left(k_{2} \exp \left(\frac{2 F \varphi_{0}}{R T}\right)-j k_{2} q_{1} \exp \left(\frac{2 F \varphi_{0}}{R T}\right)+k_{p} x\left(1-q_{1}-\right.\right. \\
& \left.q_{2}\right)^{x-1} q_{1}^{y} q_{2}^{z} \exp \left(\frac{(2(x+y+z)-2) F \varphi_{0}}{R T}\right)-y k_{p}\left(1-q_{1}-q_{2}\right)^{x} q_{1}^{y-1} q_{2}^{z} \exp \left(\frac{(2(x+y+z)-2) F \varphi_{0}}{R T}\right)+ \\
& \left.j k_{p}\left(1-q_{1}-q_{2}\right)^{x} q_{1}^{y} q_{2}^{z} \exp \left(\frac{(2(x+y+z)-2) F \varphi_{0}}{R T}\right)\right)(8)
\end{aligned}
$$




$$
\begin{aligned}
& a_{22}=\frac{1}{Q_{2}}\left(-k_{p} x\left(1-q_{1}-q_{2}\right)^{x-1} q_{1}^{y} q_{2}^{z} \exp \left(\frac{(2(x+y+z)-2) F \varphi_{0}}{R T}\right)-z k_{p}\left(1-q_{1}-\right.\right. \\
& \left.\left.q_{2}\right)^{x} q_{1}^{y} q_{2}^{z-1} \exp \left(\frac{(2(x+y+z)-2) F \varphi_{0}}{R T}\right)+l k_{p}\left(1-q_{1}-q_{2}\right)^{x} q_{1}^{y} q_{2}^{z} \exp \left(\frac{(2(x+y+z)-2) F \varphi_{0}}{R T}\right)\right)
\end{aligned}
$$

Avoiding the cumbersome expressions, we introduce new variables, rewriting the determinant as (10)

$$
\frac{1}{Q_{1} Q_{2}}\left|\begin{array}{cc}
-X-Y-Z & -S-Y \\
Y-Z & -Y
\end{array}\right|
$$

The general singular point conditions for the bivariant systems may be joined in Table 1.

Table 1. The main singular point conditions for the bivariant systems.

\begin{tabular}{l|c} 
Stable steady-state & $\operatorname{Tr} \mathrm{J}<0$, Det $\mathrm{J}>0$ \\
\hline Oscillatory behavior & $\operatorname{Tr} \mathrm{J}=0$, Det $\mathrm{J}>0$ \\
\hline Monotonic instability & $\operatorname{Tr} \mathrm{J}<0$, Det $\mathrm{J}=0$
\end{tabular}

Herein,

$$
\begin{aligned}
\operatorname{Tr} J & =-\frac{1}{Q_{1}}(X+Y+Z)-\frac{Y}{Q_{2}} \\
\operatorname{Det} J & =\frac{1}{Q_{1} Q_{2}}\left(X Y+2 Y^{2}+S Y-S Z\right)
\end{aligned}
$$

The Hopf bifurcation condition, correspondent to the oscillatory behavior, may be satisfied if the main diagonal Jacobian elements (6) and (9) contain positive elements, corresponding to the positive callback.

Two factors may be responsible for the oscillatory behavior in this case. Besides DEL influences of the electrochemical stages, leading to the cyclical changes in surface and DEL conductivities and impedances, the auto-promoted ellagic acid surface concentration decrease is also responsible for that type of behavior. The oscillation frequency and amplitude will be highly dependent on the background electrode composition and electrode nature. Mathematically, the oscillatory behavior condition for this system will be described as (13):

$$
\left\{\begin{array}{c}
-\frac{1}{Q_{1}}(X+Y+Z)=\frac{Y}{Q_{2}} \\
\frac{1}{Q_{1} Q_{2}}\left(X Y+2 Y^{2}+S Y-S Z\right)>0
\end{array}\right.
$$

As for the steady-state stability, its condition will be mathematically depicted as (14):

$$
\left\{\begin{array}{c}
-\frac{1}{Q_{1}}(X+Y+Z)<\frac{Y}{Q_{2}} \\
\frac{1}{Q_{1} Q_{2}}\left(X Y+2 Y^{2}+S Y-S Z\right)>0
\end{array}\right.
$$

The requisite (14) is satisfied in a somehow narrower topological parameter range than for similar systems. Nevertheless, it will remain wide, as the condition (14) is readily satisfied, if the kinetical parameters $\mathrm{X} \mathrm{Y,S}$, and $\mathrm{Z}$ are positive, describing the fragility of auto promoting and DEL destabilizing effects.

Really, putting $X, Y, S$, and Z $>0$, we may see that the left side of the first inequity of the set (14) will be more negative, and the left side of the left side of the second inequity of this set will be more positive. This will depict a kinetically controlled system with well-developed polymer surface formation.

The monotonic instability for this system depicts a margin between the stable steadystates and unstable states. It is correspondent to the N-shaped range of the steady-state voltammogram, and its condition will be described as: 


$$
\left\{\begin{array}{c}
-\frac{1}{Q_{1}}(X+Y+Z)<\frac{Y}{Q_{2}} \\
\frac{1}{Q_{1} Q_{2}}\left(X Y+2 Y^{2}+S Y-S Z\right)=0
\end{array}\right.
$$

As for the polymer formed during the synthesis, it is also capable of being oxidized in certain conditions. The oxidation of the resulting polymer may be realized by either the quinone-hydroquinone mechanism or the polythiophene paradox mechanism. Either way, the equation-set (1) will be insufficient to describe this type of system, and the third equation, describing the polymer coverage degree, will be added to this set, transforming it into (16):

$$
\left\{\begin{array}{c}
\frac{d q_{1}}{d t}=\frac{1}{Q_{1}}\left(r_{1}-r_{2}-r_{p}\right) \\
\frac{d q_{2}}{d t}=\frac{1}{Q_{2}}\left(r_{2}-r_{p}\right) \\
\frac{d p}{d t}=\frac{1}{P}\left(r_{p}-r_{o}\right)
\end{array}\right.
$$

The behavior of the system, described by the equation-set (16), will be even more dynamic. Its analysis will be described in our next works.

\section{Conclusions}

From the analysis of the system with the electrochemical oxidation and electropolymerization of ellagic acid, it has been possible to conclude that, despite the hybridity of the oxidation mechanism, the oxidation may be realized efficiently, yielding a welldeveloped polymer coating. The system is kinetically controlled. As for the oscillatory behavior will be more possible than for similar systems due to the action of two factors, providing the positive callback.

\section{Funding}

This research received no external funding.

\section{Acknowledgments}

This research has no acknowledgment.

\section{Conflicts of Interest}

The authors declare no conflict of interest.

\section{References}

1. Liu, X.; Liu, J. Biosensors and Sensors for Dopamine Detection. View 2021, 2, https://doi.org/10.1002/VIW.20200102.

2. Karthika, A.; Ramasamy Raja, V.; Karuppasamy, P.; Suganthi, A.; Rajarajan, M. A novel electrochemical sensor for determination of hydroquinone in water using FeWO4/SnO2 nanocomposite immobilized modified glassy carbon electrode. Arabian Journal of Chemistry 2020, 13, 40654081,https://doi.org/10.1016/j.arabjc.2019.06.008.

3. Kumar, Y.; Vashistha, V.K.; Das, D.K. Synthesis of Perovskite-type $\mathrm{NdFeO}_{3}$ nanoparticles and used as electrochemical sensor for detection of paracetamol. Lett. Appl. Nanobiosci. 2020, 9, 866-869. https://doi.org/10.33263/LIANBS91.866869.

4. Sá, A.C.d.; Barbosa, S.C.; Raymundo-Pereira, P.A.; Wilson, D.; Shimizu, F.M.; Raposo, M.; Oliveira, O.N. Flexible Carbon Electrodes for Electrochemical Detection of Bisphenol-A, Hydroquinone and Catechol in Water Samples. Chemosensors 2020, 8,https://doi.org/10.3390/chemosensors8040103.

5. Koçak, Ç. C; Koçak, S. Enhanced Electrochemical Determination of Catechol and Hydroquinone Based on Pd Nanoparticles/Poly(Taurine) Modified Glassy Carbon Electrode.Electroanalysis 2020, 32, https://doi.org/10.1002/elan.201900500. 
6. Mashhadizadeh, M.H.; Kalantarian, S.M.; Azhdeh, A. A Novel Electrochemical Sensor for Simultaneous Determination of Hydroquinone, Catechol and Resorcinol Using a Carbon Paste Electrode, Modified by ZnMOF, Nitrogen-Doped Graphite and AuNPs. Electroanalysis 2020, 32, https://doi.org/10.1002/elan.202060326

7. Al-Shar'i, N.A.; Al-Balas, Q.A.; Hassan, M.A.; El-Elimat, T.M.; Aljabal, G.A.; Almaaytah, A.M. Ellagic acid: A potent glyoxalase-I inhibitor with a unique scaffold. Acta Pharmaceutica 2021, 71, 115-130, https://doi.org/10.2478/acph-2021-0005.

8. Hering, N.A.; Luettig, J.; Jebautzke, B.; Schulzke, J.D.; Rosenthal, R. The Punicalagin Metabolites Ellagic Acid and Urolithin A Exert Different Strengthening and Anti-Inflammatory Effects on Tight JunctionMediated Intestinal Barrier Function In Vitro. Frontiers in Pharmacology 2021, 12, https://doi.org/10.3389/fphar.2021.610164.

9. Li, Y.; Mei, L.; Guan, X.; Hu, Y. Ellagic acid solid dispersion: Characterization and bioactivity in the hydroxyl radical oxidation system. Food Research International 2021, 142, https://doi.org/10.1016/j.foodres.2021.110184.

10. Melgarejo-Sánchez, P.; Núñez-Gómez, D.; Martínez-Nicolás, J.J.; Hernández, F.; Legua, P.; Melgarejo, P. Pomegranate variety and pomegranate plant part, relevance from bioactive point of view: a review. Bioresources and Bioprocessing 2021, 8,https://doi.org/10.1186/s40643-020-00351-5.

11. Moga, M.A.; Dimienescu, O.G.; Bălan, A.; Dima, L.; Toma, S.I.; Bîgiu, N.F.; Blidaru, A. Pharmacological and Therapeutic Properties of Punica granatum Phytochemicals: Possible Roles in Breast Cancer. Molecules 2021, 26,https://doi.org/10.3390/molecules26041054.

12. Ziyatdinova, G.; Guss, E.; Morozova, E.; Budnikov, H.; Davletshin, R.; Vorobev, V.; Osin, Y. Simultaneous voltammetric determination of gallic and ellagic acids in cognac and brandy using electrode modified with functionalized SWNT and poly(pyrocatechol violet). Food Analytical Methods 2019, 12, 2250-2261, https://doi.org/10.1007/s12161-019-01585-6.

13. Sabbaghi, N.; Noroozifar, M.; Kerman, K. Nanocomposite of Ellagic Acid with Multi-Walled Carbon Nanotubes for the Simultaneous Voltammetric Detection of Six Biomolecules. C 2021, 7, https://doi.org/10.3390/c7020043.

14. Manjunatha, J. Poly(Adenine) Modified Graphene-Based Voltammetric Sensor for the Electrochemical Determination of Catechol, Hydroquinone and Resorcinol.The Open Chemical Engineering Journal 2020, 14, 52-62,https://doi.org/10.2174/1874123102014010052.

15. Ahmad, K.; Kumar, P.; Mobin, S.M. A highly sensitive and selective hydroquinone sensor based on a newly designed $\mathrm{N}-\mathrm{rGO} / \mathrm{SrZrO} 3 \quad$ composite. Nanoscale Advances $\mathbf{2 0 2 0}, \quad 2, \quad 502-$ 511,https://doi.org/10.1039/c9na00573k.

16. Romero-Montero, A.; del Valle, L.J.; Puiggalí, J.; Montiel, C.; García-Arrazola, R.; Gimeno, M. Poly(gallic acid)-coated polycaprolactone inhibits oxidative stress in epithelial cells. Materials Science and Engineering: C 2020, 115,https://doi.org/10.1016/j.msec.2020.111154.

17. Zamudio-Cuevas, Y.; Andonegui-Elguera, M.A.; Aparicio-Juárez, A.; Aguillón-Solís, E.; Martínez-Flores, K.; Ruvalcaba-Paredes, E.; Velasquillo-Martínez, C.; Ibarra, C.; Martínez-López, V.; Gutiérrez, M.; GarcíaArrazola, R.; Hernández-Valencia, C.G.; Romero-Montero, A.; Hernández-Valdepeña, M.A.; Gimeno, M.; Sánchez-Sánchez, R. The enzymatic poly(gallic acid) reduces pro-inflammatory cytokines in vitro, a potential application in inflammatory diseases. Inflammation 2021, 44, 174-185, https://doi.org/10.1007/s10753-02001319-5.

18. Yang, P.; Zhang, S.; Chen, X.; Liu, X.; Wang, Z.; Li, Y. Recent developments in polydopamine fluorescent nanomaterials. Materials Horizons 2020, 7, 746-761, https://doi.org/10.1039/c9mh01197h.

19. Das, I.; Goel, N.; Agrawal, N.R.; Gupta, S.K. Growth patterns of dendrimers and electric potential oscillations during electropolymerization of pyrrole using mono-and mixed surfactants. J. Phys. Chem. B 2010, 114, 12888-12896, https://doi.org/10.1021/jp105183q

20. Das, I.; Goel, N.; Gupta, S.K.; Agrawal, N.R. Electropolymerization of pyrrole: Dendrimers, nano-sized patterns and oscillations in potential in presence of aromatic and aliphatic surfactants. J. Electroanal. Chem.2012, 670, 1-10, https://doi.org/10.1016/j.jelechem.2012.01.023.

21. Tkach, V.V.; Kushnir, M.V.; Ivanushko, Y.G.; de Oliviera, S.The Theoretical Description for Neotame Electrochemical Determination, Assisted by Vanadium Oxyhydroxide Composite with a Squarainic Dye. Appl. J. Env. Eng. Sci. 2020, 6, 109-115.

22. Tkach, V.V.; Kushnir, M.V.; Storoshchuk, N.M.; Ivanushko, Y. The Theoretical Description for the Confection of the Novel Thiourea-Based Active Surface for Cathodic Conducting Polymer Deposition. Appl. J. Env. Eng. Sci.2020, 6, 143-148.

23. Tkach, V.; Kushnir, M.; Ivanushko, Y.; de Oliveira, S.; Reis, L.; Yagodynets', P.; Kormosh, Z.The Theoretical Description for the Electrochemical Synthesis of Squaraine Dye Doped Conducting Polymer. Appl. J. Env. Eng. Sci. 2020, 6, 51-56.

24. Tkach, V.V.; Storoshchuk, N.M.; Romaniv, L.V.; De Oliveira, S.C.; Luganska, O.V.; Gala, H.B.; Tchikuala, E.F.; Yagodynets, P.I.The theoretical evaluation of the poly (3, 4'dimetylpyrrole) cathodic electrodeposition assisted by manganate ions. Vietnam.J..Chem.2018, 56, 440-444, https://doi.org/10.1002/vjch.201800027. 